\title{
Antiobesity and hypolipidemic effects of lotus leaf hot water extract with taurine supplementation in rats fed a high fat diet
}

\author{
Huan $\mathrm{Du}^{1 \dagger}$, Jeong-Soon $\mathrm{You}^{1 \dagger}, \mathrm{Xu}_{\text {Zhao }}{ }^{1 \dagger}$, Ji-Yeon Park ${ }^{1 \dagger}$, Sung-Hoon Kim ${ }^{2 \dagger}$, Kyung-Ja Chang ${ }^{{ }^{*}}$ \\ From $17^{\text {th }}$ International Meeting of Taurine \\ Fort Lauderdale, FL, USA. 14-19 December 2009
}

\begin{abstract}
Background: Lotus (Nelumbo nucifera) leaf has been used to treat obesity. The purpose of this study was to investigate the antiobesity and hypolipidemic effects of lotus leaf hot water extract with taurine supplementation in high fat diet-induced obese rats.

Methods: Four week-old male Sprague-Dawley rats were randomly divided into four groups with 8 rats in each group for a period of 6 weeks (normal diet, N group; high fat diet, HF group; high fat diet + lotus leaf hot water extract, HFL group; high fat diet + lotus leaf hot water extract + taurine, HFLT group). Lotus leaf hot water extract was orally administrated to HFL and HFLT groups and the same amount of distilled water was orally administered (400 mg/kg/day) to $\mathrm{N}$ and HF groups. Taurine was supplemented by dissolving in feed water (3\% w/v).

Results: The body weight gain and relative weights of epididymal and retroperitoneal adipose tissues were significantly lower in N, HFL and HFLT groups compared to HF group. HFL and HFLT groups showed lower concentrations of total cholesterol, triglyceride and low density lipoprotein cholesterol in serum. HFLT group showed higher the ratio of high density lipoprotein cholesterol/total cholesterol compared to HFL group. HFLT group showed better blood lipid profiles compared to HFL group.
\end{abstract}

\section{Conclusions}

Lotus leaf hot water extract with taurine supplementation showed antiobesity and hypolipidemic effects in high fat diet-induced obese rats, which was more effective than lotus leaf hot water extract alone.

\section{Background}

Recently it has been reported that high fat diets are responsible for high global prevalence of obesity [1,2]. It is well-known that obesity is associated with many chronic diseases in both humans and laboratory animals such as diabetes mellitus, cardiovascular disease, digestive disease, respiratory disease and various cancers [3-5]. Obesity induced by high fat intake is usually accompanied by hyperlipidemia [6] which presents as an abnormally high concentration of lipids in blood. Generally, this abnormally high concentration of lipids in

\footnotetext{
* Correspondence: kjchang@inha.ac.kr

+ Contributed equally

'Department of Food and Nutrition, Inha University, Incheon, Korea

Full list of author information is available at the end of the article
}

blood means elevated blood total cholesterol (TC) and/ or triglyceride (TG) levels [7]. Although hyperlipidemia does not cause any symptoms by itself, these abnormally high blood lipids levels can lead to various cardiovascular diseases (CVD) such as atherosclerosis and coronary heart disease (CHD) [8] which together are one of the most common causes of death in modern society [9].

Nelumbo nucifera, known as the sacred lotus, has many medicinal uses in traditional cultures. Previous studies showed that various pharmacologically active substances were separated from different parts of lotus mainly including alkaloids, flavonoids, triterpenoids, polyphenols, steroids and glycosides [10]. Among the different parts, lotus leaf showed a concentration-dependent inhibition of the activities of $\alpha$-amylase and lipase, 
and up-regulated lipid metabolism [11]. Taurine (2-aminoethane sulfonic acid) is abundant in the tissues of most mammalians including humans[12,13] and blood taurine concentration was lowered in the obese mice [14]. Taurine supplementation can improve serum lipid profiles in rats [15] and mice[16], and decrease serum TG concentration in overweight or obese humans[17]. In addition, both lotus leaf and taurine have highly safe properties, and can be served as raw materials for functional foods with antiobesity. Therefore, this research was conducted to evaluate antiobesity and hypolipidemic effects of lotus leaf hot water extract with taurine supplementation in rats fed a high fat diet.

\section{Methods}

\section{Animals and diet}

Three-week old male Sprague-Dawley rats were purchased from Hyundai-Bio (Anseong, Korea). All rats were kept at laboratory animal housing at Inha University following the recommendation of the Guide for the Care and Use of Laboratory Animals (Resources 1996) with a constant $12 \mathrm{~h}$ light and dark cycle (AM 09:00 PM 09:00), controlled temperature $\left(23 \pm 1^{\circ} \mathrm{C}\right)$ and humidity (55 $\pm 10 \%)$. Following one week of acclimatization with a pelletized commercial diet, rats were randomly divided into four groups $(\mathrm{n}=8)$ for a period of 6 weeks (normal diet, $\mathrm{N}$ group; high fat diet, HF group; high fat diet + lotus leaf hot water extract, HFL group; high fat diet + lotus leaf hot water extract + taurine, HFLT group). Lotus leaf hot water extract was orally administrated to HFL and HFLT groups and the same amount of distilled water was orally administered to $\mathrm{N}$ and HF groups. Taurine was supplemented by dissolving in feed water $(3 \% \mathrm{w} /$ v). Food and water intakes were measured everyday and body weight was measured once every two days. The composition of the experimental diet was based on AIN76 [18] as shown in Table 1.

\section{Preparation of lotus leaf hot water extract}

Dried powder of lotus leaf was purchased from Seonwon Temple (Ganghwa-gun, Incheon, Korea). Lotus sample was extracted by water at $90^{\circ} \mathrm{C}$ with a solid-liquid ratio of $2.5 \mathrm{~g} / 100 \mathrm{ml}$ for 2 hours. After vacuum filtration, the extract was introduced into a rotary evaporator (Büchi Laboratoriums Teknik, Switzerland). The concentrated liquid was dried by using a freeze dryer (Ilshin, Korea). The brown powder was obtained with $18.8 \%$ extraction yield and it was stored at $-20^{\circ} \mathrm{C}$ until application.

\section{Sampling and chemical analysis}

After six weeks, the animals were fasted for 12 hours before sacrifice. Blood was collected from the heart and serum was obtained by centrifugation at $3000 \mathrm{rpm}$ for 20 minutes. The liver, kidney, spleen, epididymal fat
Table 1 Composition of experimental diets ( $\mathrm{g} / 100 \mathrm{~g}$ diet)

\begin{tabular}{lll}
\hline Ingredients & \multicolumn{2}{c}{ Experimental diets } \\
\cline { 2 - 3 } & Normal Diet & High Fat Diet \\
\hline
\end{tabular}

\begin{tabular}{lcc} 
Choline bitartrate & 0.2 & 0.2 \\
DL-Methione & 0.3 & 0.3 \\
Vitamin mixture & 1 & 1 \\
Mineral mixture & 3.5 & 3.5 \\
Cellulose & 5 & 5 \\
Sucrose & 50 & 40 \\
Corn starch & 15 & 10 \\
Casein & 20 & 20 \\
Bean oil & 5 & 5 \\
Lard & 0 & 15 \\
\hline Carbohydrate (kcal / 100g) & 260 & 200 \\
Protein (kcal / 100g) & 85 & 85 \\
Fat (kcal /100g) & 45 & 180 \\
Total calories (kcal / 100g) & 390 & 465 \\
\hline
\end{tabular}

Vitamin Mixture $(\mathrm{g} / \mathrm{kg})$; thiamin hydrochloride $600 \mathrm{mg}$, riboflavin $600 \mathrm{mg}$, pyridoxine hydrochloride $700 \mathrm{mg}$, nicotinic acid $3 \mathrm{~g}$, D-calcium pantothenate $1.6 \mathrm{~g}$, folic acid $200 \mathrm{mg}$, D-biotin $20 \mathrm{mg}$, cyanocobalamin $1 \mathrm{mg}$ retinyl palmitate pre-mix $(250,000 \mathrm{lU} / \mathrm{g}) 1.6 \mathrm{~g}$, DL-alpha-tocopherol acetate $(250 \mathrm{IU} / \mathrm{g}) 20 \mathrm{~g}$, cholecalciferol $(400,000 \mathrm{IU} / \mathrm{g}) 250 \mathrm{mg}$, menaquinone $5 \mathrm{mg}$ sucrose, finely powdered $972.9 \mathrm{~g}$, Mineral mixture $(\mathrm{g} / \mathrm{kg})$; calcium phosphate dibasic $500 \mathrm{~g}$, sodium chloride $74 \mathrm{~g}$, potassium citrate monohydrate $220 \mathrm{~g}$, potassium sulfate $52 \mathrm{~g}$, magnesium oxide $24 \mathrm{~g}$, manganous carbonate $(43 \sim 48 \% \mathrm{Mn}) 3.5 \mathrm{~g}$, ferric citrate $(16 \sim 17 \% \mathrm{Fe}) 6 \mathrm{~g}$, zinc carbonate $(70 \% \mathrm{ZnO}) 1.6 \mathrm{~g}$, cupric carbonate (53 $55 \% \mathrm{Cu}) 0.3 \mathrm{~g}$, potassium iodate $0.01 \mathrm{~g}$, sodium selenite $0.01 \mathrm{~g}$, chromium potassium sulfate $0.55 \mathrm{~g}$, sucrose finely powdered $118 \mathrm{~g}$.

(E-fat) and retroperitoneal fat (R-fat) were weighed. Some of E-fat was removed from the rats for histological photograph. The serums were immediately frozen in liquid nitrogen, and then stored at $-70^{\circ} \mathrm{C}$ until application (Operon, Korea).

Concentrations of serum TG and total TC were analyzed using automatic analyzer (BPC BioSed srl, Italy). High-density lipoprotein-cholesterol (HDL-C) was obtained from the whole serum with high density lipoprotein precipitation reagent (AM204-1, Asan Pharmaceutical, Korea) after precipitation of low-density lipoprotein and very-low-density lipoprotein for $10 \mathrm{~min}$ utes at 3000rpm (Hettich Mikro 200R, Tuttlingen, Germany) [19] and then analyzed for HDL-C using the same method as with TC. Further, the ratio of HDL-C/ TC was calculated. Serum low-density lipoprotein cholesterol(LDL-C) value was calculated by using the Friedewald formula [20] as follows:

\section{LDL- C=TC-(HDL-C + TG/5)}

Standard serum (lot no. 053801, Asan Pharmaceutical, Korea) was used for calibration before every parameter was analyzed. All of the results were expressed as $\mathrm{mg} / \mathrm{dl}$ serum.

Histological photograph of adipose tissue was analyzed based on the paraffin method using a light microscope. Fresh tissues were fixed immediately in Bouin's solution 
for 6-12 hours and then fixed tissue was washed under running water. After being dehydrated through different grades of alcohol, the tissues were embedded in paraffin block at $60^{\circ} \mathrm{C}$. Eight $\mu \mathrm{m}$ sections were cut and mounted on glass slides coated with an egg albumin and then the paraffin was removed with xylen and alcohol. The glass slides were stained with hematoxylin and eosin. After being dehydrated and cleared by alcohol and xylen, the glass slides were mounted in Canada Balsam. Photomicrographs were taken with a Zeiss Axiolab light microscope equipped with a Nikon Microflex HFX microscope camera. The size of epdidymal adipocyte was calculated by Image-Pro Plus 6.0 (Media Cybernetics, Maryland, USA) and the results were expressed as pixels per epdidymal adipocyte.

\section{Statistical analysis}

Data were analyzed for significant difference by one-way analysis of variance followed by Duncan's multiple range tests at a $\mathrm{p}<0.05$. All analyses were performed using SPSS 17.0 program.

\section{Results and discussion}

\section{Body weight, diet intake and food efficiency ratio}

After 3 weeks, body weight of HF group was significantly higher compared to other groups (Figure 1). The food intakes of $\mathrm{N}$ and $\mathrm{HF}$ groups were higher compared to HFL and HFLT groups. The food efficiency ratio (FER) of $\mathrm{N}$ group was significantly lower compared to other groups (Table 2). These results suggest that lotus leaf hot water extract and taurine may prevent an increase of body weight induced by a high fat diet; it seemed that low body weight in HFL and HFLT groups

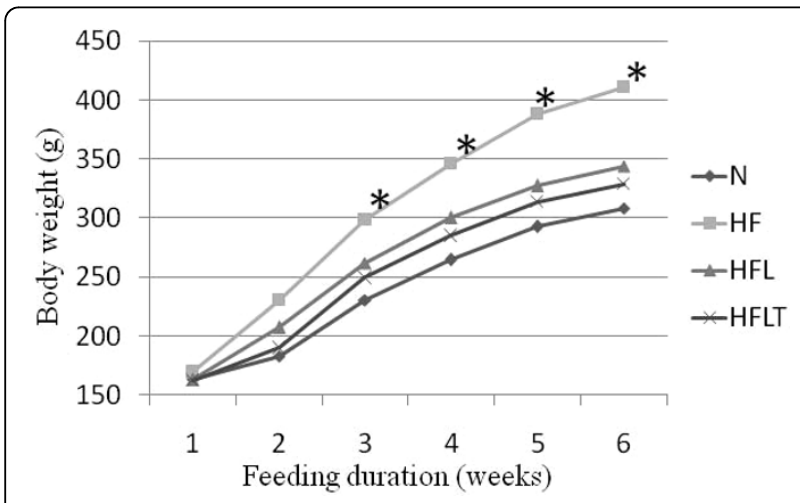

Figure 1 Effect of lotus leaf hot water extract with taurine on body weight Average body weights were analyzed by one-way analysis by one way analysis of variance followed by Duncan's multiple range tests at $p<0.05$. Superscript stars means that body weight in HF group was significantly higher compared to other groups. N, normal diet group; HF, high fat diet group; HFL, high fat diet + lotus leaf hot water extract group; HFLT, high fat diet + lotus leaf hot water extract + taurine group.
Table 2 Effect of lotus leaf hot water extract with taurine on water intake and FER

\begin{tabular}{lccccccccc}
\hline Group & \multicolumn{3}{c}{ Water intake (g/day) } & \multicolumn{3}{c}{ Diet intake (g/day) } & \multicolumn{3}{c}{ FER (\%) } \\
\hline $\mathrm{N}$ & 29.9 & \pm & $1.7^{\mathrm{ns}}$ & 20.4 & \pm & $0.6^{\mathrm{a}}$ & 24.9 & \pm & $0.3^{\mathrm{a}}$ \\
$\mathrm{HF}$ & 30.8 & \pm & 2.7 & 22.0 & \pm & $0.6^{\mathrm{a}}$ & 29.3 & \pm & $1.0^{\mathrm{b}}$ \\
$\mathrm{HFL}$ & 31.3 & \pm & 1.6 & 17.5 & \pm & $0.8^{\mathrm{b}}$ & 29.6 & \pm & $0.5^{\mathrm{b}}$ \\
$\mathrm{HFLT}$ & 35.4 & \pm & 2.0 & 15.6 & \pm & $1.0^{\mathrm{b}}$ & 30.1 & \pm & $0.6^{\mathrm{b}}$ \\
\hline
\end{tabular}

FER: Food efficiency ratio (FER (\%) $=$ [total body weight gain (g) / total food intake $(\mathrm{g})] \times 100 \%$ ); Values are mean $\pm \mathrm{SE}$; Values with different superscripts within the column are significantly different at $p<0.05$ by Duncan's multiple range test.

partially due to loss of appetite. In order to understand change of appetite by ingesting lotus leaf hot water extract and taurine, further research will be done.

\section{Organ and adipose tissue weight}

The absolute weights of liver, spleen and kidney of HF group were significantly higher compared to other groups. However, there was no significant difference in the relative weight of liver and spleen among groups (additional file 1). Adipose tissue is considered as the biggest storage site for excess energy [21]. The adipose tissue weights (E-fat and R-fat) of HF group were significantly higher compared to other groups. Both absolute and relative retroperitoneal fat weights were significantly decreased around 50\% less in HFL and HFLT groups compared to HF group (additional file 2). Therefore, lotus leaf hot water extract alone or with taurine supplementation may inhibit the increase of body fat induced by a high fat diet in rats.

\section{Serum lipid profiles}

Serum lipid profiles are shown in additional file 3 . The concentrations of serum TG, TC and LDL-C were significantly lower in HFL and HFLT groups compared to HF group. Lotus leaf hot water extract alone or with taurine supplementation has effects of decreasing the concentration of serum TG, TC and LDL-C, and of increasing the ratio of HDL-C/TC. These results are in agreement with previous results[11,22,23] and suggest that combined supplementation of lotus leaf hot water extract and taurine showed better blood lipid profiles compared to lotus leaf hot water extract alone.

\section{Histological photograph}

Excessive growth of adipose tissue results in obesity which includes two growth mechanisms: hyperplastic (cell number increase) and hypertrophic (cell size increase) [24]. The histological appearance of epdidymal adipocyte was irregular in HF group compared to $\mathrm{N}$ group. However, this morphological change did not appear in HFL and HFLT groups (Figure 2). The sizes of epdidymal adipocytes were significantly bigger in $\mathrm{HF}$ 

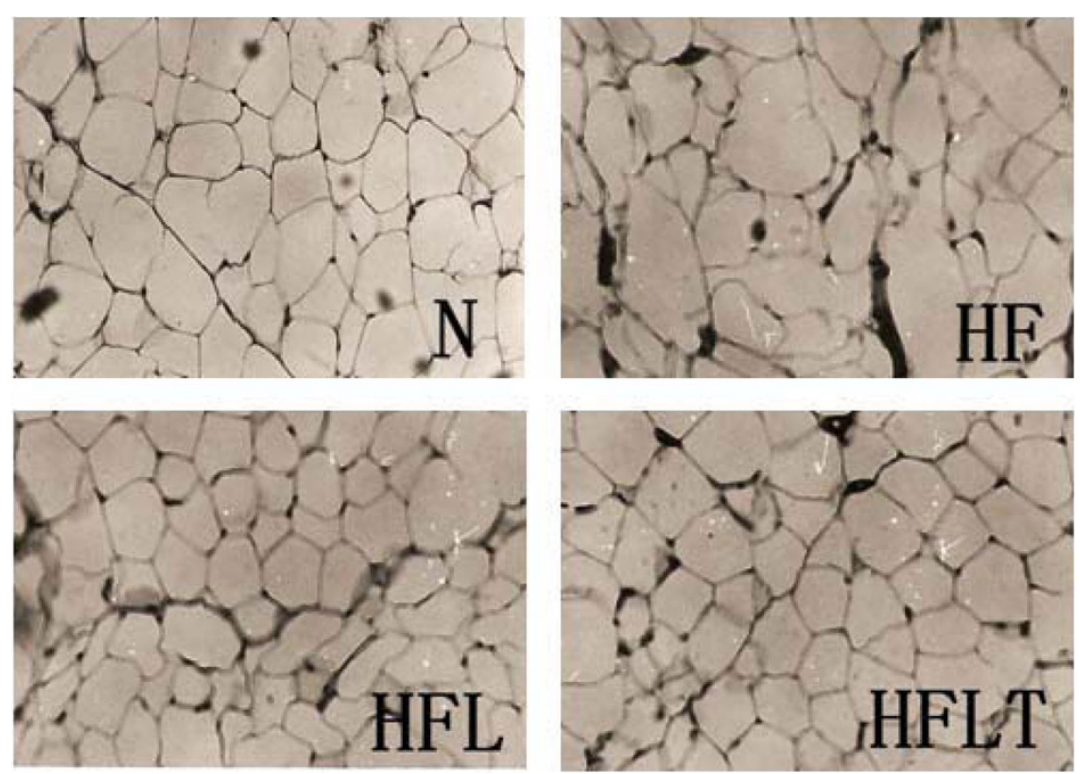

Figure 2 Effect of lotus leaf hot water extract with taurine on epididymal adipocytes Histological photograph: Histological photograph of epididymal adipocytes is fed a normal rats' diet or a high fat rats' diet with supplementation of lotus leaf hot water extract alone or lotus leaf hot water extract with taurine. Magnification $\times 200$. There was morphological change in HF group compared to other groups. $N$, normal diet group; HF, high fat diet group; HFL, high fat diet + lotus leaf hot water extract group; HFLT, high fat diet + lotus leaf hot water extract + taurine group.

group compared to other groups and the HFL and HFLT groups showed similar adipocyte size to that of $\mathrm{N}$ group (Figure 3). These results suggest that lotus leaf hot water extract alone or with taurine supplementation can inhibit lipid accumulation in epididymal adiypocyte tissue.

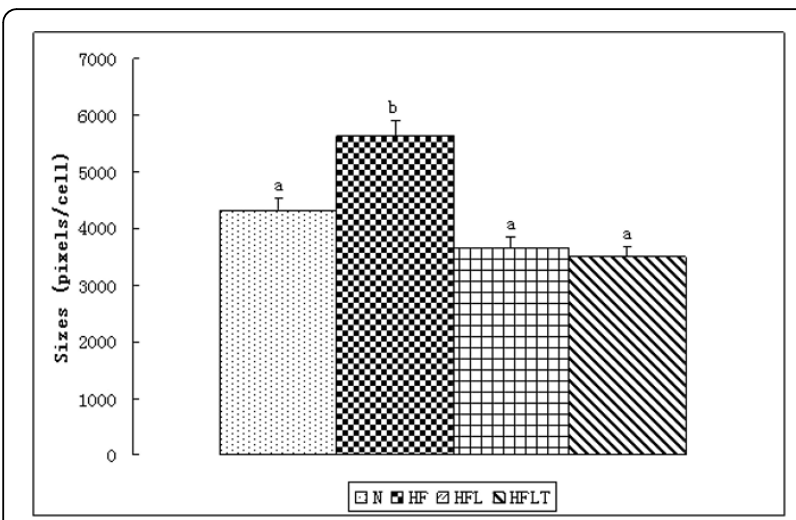

Figure 3 Effect of lotus leaf hot water extract with taurine on epididymal adipocytes Sizes of epididymal adipocytes: Effect of lotus leaf hot water extract with taurine supplementation on sizes of epididymal adipocytes in rats fed a normal diet or a high fat diet. Calculation by stochastic 10 cells by Image-Pro Plus 6.0. Data were presented as mean $\pm \mathrm{SE}$. Values with different superscripts are significantly different at $p<0.05$ by Duncan's multiple range tests. The size in HF group is significantly bigger compared to other groups. N, normal diet group; HF, high fat diet group; HFL, high fat diet + lotus leaf hot water extract group; HFLT, high fat diet + lotus leaf hot water extract + taurine group.

\section{Conclusions}

In conclusion, our results suggest that supplementation of lotus leaf hot water extract and taurine shows antiobesity and hypolipidemic effects in diet-induced obese rats.

Combined supplementation of lotus leaf hot water extract and taurine showed a better effect on blood lipid profiles as compared to lotus leaf hot water extract alone.

\section{Additional material}

Additional file 1: Effect of lotus leaf hot water extract with taurine on organ weights. PDF.

Additional file 2: Effect of lotus leaf hot water extract with taurine on adipose tissue weights. PDF.

Additional file 3: Effect of lotus leaf hot water extract with taurine on serum lipid profile. PDF.

\section{Abbreviations}

FER: Food efficiency ratio (FER (\%) = [total body weight gain $(\mathrm{g}) /$ total food intake $(\mathrm{g})$ ] $\times 100 \%)$; E-fat: epididymal fat; R-fat: retroperitoneal fat; TG: triglyceride; TC: total-cholesterol; HDL-C: high density lipoprotein-cholesterol; LDL-C: low density lipoprotein-cholesterol: TC-(HDL-C+TG/5); HDL-C/TC: ratio of $\mathrm{HDL}-\mathrm{C} /$ Total Cholesterol.

\section{Acknowledgements}

This article has been published as part of Journal of Biomedical Science Volume 17 Supplement 1, 2010: Proceedings of the 17th International Meeting of Taurine. The full contents of the supplement are available online at http://www.jbiomedsci.com/supplements/17/S1. 
We thank the Dong-A Pharmaceutical Co. which donated taurine.

\section{Author details}

'Department of Food and Nutrition, Inha University, Incheon, Korea.

${ }^{2}$ Department of Chemistry, Konkuk University, Seoul, Korea.

\section{Authors' contributions}

HD carried out design, execution, statistical analysis, manuscript preparation and total coordination of the study. JSY, XZ, and JYP participated in discussion, data collection, and analysis. SHK provided a method for extracting lotus leaf. KJC guided in the design and execution of the study. All authors read and approved the final manuscript.

\section{Competing interests}

The authors declare that they have no competing interests.

Published: 24 August 2010

\section{References}

1. Martinez J, Kearney J, Kafatos A, Paquet S, Martinez-Gonzelez M: Variables independently associated with self-reported obesity in the European Union. Public Health Nutr 2007, 2:125-133.

2. Prentice $A$ : The emerging epidemic of obesity in developing countries. International Journal of epidemiology 2006, 35:93.

3. Calle E, Rodriguez C, Walker-Thurmond K, Thun M: Overweight, Obesity, and Mortality from Cancer in a Prospectively Studied Cohort of US Adults. 2003, 348:1625-1638.

4. Mokdad A, Ford E, Bowman B, Dietz W, Vinicor F, Bales V, Marks J: Prevalence of Obesity, Diabetes, and Obesity-Related Health Risk Factors, 2001. JAMA 2003, 289:76-79.

5. Must A, Spadano J, Coakley E, Field A, Colditz G, Dietz W: The Disease Burden Associated With Overweight and Obesity. JAMA 1999, 282:1523-1529.

6. Akiyama T, Tachibana I, Shirohara H, Watanabe N, Otsuki M: High-fat hypercaloric diet induces obesity, glucose intolerance and hyperlipidemia in normal adult male Wistar rat. Diabetes Res Clin Pract 1996, 31:27-35.

7. Smith A, Datta S, Smith G, Campbell P, Bentley R, McKenzie H, Jakoby W: Oxford dictionary of biochemistry and molecular biology. Oxford University Press London 1997.

8. Bonora E, Kiechl S, Willeit J, Oberhollenzer F, Egger G, Bonadonna R, Muggeo M: Carotid atherosclerosis and coronary heart disease in the metabolic syndrome. Diabetes Care 2003, 26:1251.

9. Smith S, Allen J, Blair S, Bonow R, Brass L, Fonarow G, Grundy S, Hiratzka L, Jones $D$, Krumholz $\mathrm{H}$ : AHA/ACC guidelines for secondary prevention for patients with coronary and other atherosclerotic vascular disease: 2006 update endorsed by the National Heart, Lung, and Blood Institute. Journal of the American College of Cardiology 2006, 47:2130-2139.

10. Mukherjee P, Mukherjee D, Maji A, Rai S, Heinrich M: The sacred lotus (Nelumbo nucifera)-phytochemical and therapeutic profile. J Pharm Pharmacol 2009, 61:407-422.

11. Ono $Y$, Hattori $E$, Fukaya $Y$, Imai S, Ohizumi $Y$ : Anti-obesity effect of Nelumbo nucifera leaves extract in mice and rats. Journal of Ethnopharmacology 2006, 106:238-244.

12. Bouckenooghe T, Remacle C, Reusens B: Is taurine a functional nutrient? Curr Opin Clin Nutr Metab Care 2006, 9:728-733.

13. Brosnan J, Brosnan M: The sulfur-containing amino acids: an overview. Journal of Nutrition 2006, 136:1636S.

14. Tsuboyama-Kasaoka N, Shozawa C, Sano K, Kamei Y, Kasaoka S, Hosokawa Y, Ezaki O: Taurine (2-aminoethanesulfonic acid) deficiency creates a vicious circle promoting obesity. Endocrinology 2006, 147:3276.

15. Choi M, Kim J, Chang K: The effect of dietary taurine supplementation on plasma and liver lipid concentrations and free amino acid concentrations in rats fed a high-cholesterol diet. Adv Exp Med Biol 2006, 583:235-242.

16. Matsushima $Y$, Sekine $T$, Kondo $Y$, Sakurai T, Kameo K, Tachibana M, Murakami S: Effects of taurine on serum cholesterol levels and development of atherosclerosis in spontaneously hyperlipidaemic mice. Clin Exp Pharmacol Physiol 2003, 30:295-299.
17. Zhang M, Bi L, Fang J, Su X, Da G, Kuwamori T, Kagamimori S: Beneficial effects of taurine on serum lipids in overweight or obese non-diabetic subjects. Amino acids 2004, 26:267-271.

18. Bieri J, Stoewsand G, Briggs G, Phillips R, Woodard J, Knapka J: Report of the American Institute of Nutrition ad hoc committee on standards for nutritional studies. J Nutr 1977, 107:1340-1348.

19. Warnick $G$, Albers J: A comprehensive evaluation of the heparinmanganese precipitation procedure for estimating high density lipoprotein cholesterol. J Lipid Res 1978, 19:65-76.

20. Friedewald W, Levy R, Fredrickson D: Estimation of the concentration of low-density lipoprotein cholesterol in plasma, without use of the preparative ultracentrifuge. Clinical Chemistry 1972, 18:499-502.

21. Large $V$, Peroni $O$, Letexier $D$, Ray $H$, Beylot M: Metabolism of lipids in human white adipocyte. Diabetes Metab 2004, 30:294-309.

22. Chang K: Effects of Taurine and $\beta$-alanine on Blood Glucose and Blood Lipid Concentrations in Streptozotocin-induced Diabetic Rats. the Korea Journal of Nutrition 1999, 32:8.

23. Onishi E, Yamada $K$, Yamada $T$, Kaji $K$, Inoue $H$, Seyama $Y$, Yamashita $S$ : Comparative effects of crude drugs on serum lipids. Chem Pharm Bull (Tokyo) 1984, 32:646-650.

24. Björntorp P: Number and size of adipose tissue fat cells in relation to metabolism in human obesity. Metabolism: clinical and experimental 1971 20:703.

doi:10.1186/1423-0127-17-S1-S42

Cite this article as: Du et al.: Antiobesity and hypolipidemic effects of lotus leaf hot water extract with taurine supplementation in rats fed a high fat diet. Journal of Biomedical Science 2010 17(Suppl 1):S42.

\section{Submit your next manuscript to BioMed Central and take full advantage of:}

- Convenient online submission

- Thorough peer review

- No space constraints or color figure charges

- Immediate publication on acceptance

- Inclusion in PubMed, CAS, Scopus and Google Scholar

- Research which is freely available for redistribution

Submit your manuscript at www.biomedcentral.com/submit
C) Biomed Central 